Supplement of Geosci. Model Dev., 15, 315-333, 2022

https://doi.org/10.5194/gmd-15-315-2022-supplement

(C) Author(s) 2022. CC BY 4.0 License.

(c) (i)

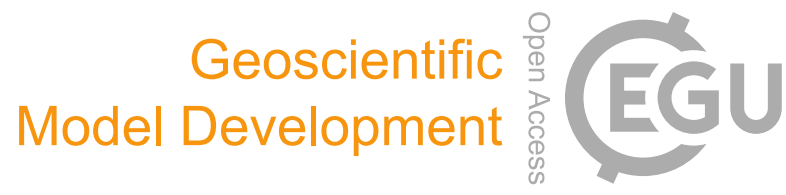

Supplement of

\title{
BioRT-Flux-PIHM v1.0: a biogeochemical reactive transport model at the watershed scale
}

\section{Wei Zhi et al.}

Correspondence to: Li Li (lili@engr.psu.edu)

The copyright of individual parts of the supplement might differ from the article licence. 
21 Where $K_{i, \text { rechg }}[\mathrm{m} / \mathrm{s}]$ is the recharge hydraulic conductivity from the shallow zone to the

22 deep zone; $d_{i}^{d p}[\mathrm{~m}]$ is the thickness of the deep zone; $K_{i, V}^{d p}[\mathrm{~m} / \mathrm{s}]$ is the vertical hydraulic 23 conductivity (i.e., considering macropore and soil matrix, see Eqn. S7-S8 later) of the

Where $\theta_{i}^{d p}\left[\mathrm{~m}^{3} / \mathrm{m}^{3}\right]$ is the deep zone porosity in the element $i ; h_{i, u}^{d p}$ and $h_{i, s}^{d p}$ [m] are the unsaturated and saturated storages in the deep zone, respectively; $q_{i, r e c h g}[\mathrm{~m} / \mathrm{s}]$ is the recharge from the shallow zone; $q_{i, u 2 s}^{d p}[\mathrm{~m} / \mathrm{s}]$ is the flux from the unsaturated to the saturated layer in the deep zone; $q_{i j}^{d p}[\mathrm{~m} / \mathrm{s}]$ is the lateral flux between element $i$ and its neighbor $j\left(N_{i j} \leq 3\right)$ in the deep zone.

The deep normalized lateral flow is calculated using Darcy's law:

$$
q_{i j}^{d p}=K_{i j}^{d p} \frac{H_{i, s}^{d p}-H_{j, s}^{d p}}{d_{i j}}
$$

Where $H_{i, s}^{d p}[\mathrm{~m}]$ is the hydraulic water head in the deep zone; $K_{i j}^{d p}[\mathrm{~m} / \mathrm{s}]$ is the harmonic mean of the deep hydraulic conductivity in the horizontal direction between elements $i$ $\left(K_{i, H}^{d p}\right)$ and $j\left(K_{j, H}^{d p}\right)$. zone:

Deep fluxes are similarly calculated using the Richards equation as in the shallow

$$
\begin{gathered}
q_{i, \text { rechg }}=K_{i, \text { rechg }} \frac{H_{i, s}^{s l}-H_{i, u}^{d p}}{0.5\left[H_{i, s}^{s l}+\left(d_{i}^{d p}-H_{i, s}^{d p}\right)\right]} \\
q_{i, u 2 s}^{d p}=K_{i, V}^{d p} \frac{H_{i, u}^{d p}-H_{i, s}^{d p}}{0.5 d_{i}^{d p}} \quad(S 5)
\end{gathered}
$$


24 deep zone; $0.5\left[H_{i, s}^{s l}+\left(d_{i}^{d p}-H_{i, s}^{d p}\right)\right]$ is the distance between the center of shallow

25 saturated zone and the center of the deep unsaturated zone (i.e., $d_{i}^{d p}-H_{i, s}^{d p}$ ).

The deep groundwater can also come from regional groundwater aquifers, which can be set up as an influx for the boundary elements of the domain. Deep groundwater interacts with river channel. When the level of deep groundwater is higher than the depth to the deep zone, i.e., the shallow transient groundwater and the deep groundwater are connected, the deep groundwater can flow into the transient saturated layer in the shallow zone:

$$
q_{i, r e c h g}=-K_{i, s a t V}^{d p}
$$

33

Where $K_{i, s a t V}^{d p}[\mathrm{~m} / \mathrm{s}]$ is the saturated hydraulic conductivity in the vertical direction of the deep zone.

Macropores. Macropores, including roots and soil cracks are ubiquitously present in soils. The model can simulate macropore flows and account for preferential water flows in the shallow zone (Shi et al., 2013). Macropore properties include depth $\left(d_{m a c}[\mathrm{~m}]\right)$ and vertical and horizontal area fraction ( $f_{\text {mact }}$ and $\left.f_{\text {mact }}[\%]\right)$ that are perpendicular to horizontal and vertical hydraulic conductivity $\left(K_{m a c H}\right.$ and $\left.K_{m a c V}\right)$, respectively. The macropore depth differs from the rooting depth that specifies the maximum depth of transpiration.

The default $K_{m a c V}$ and $K_{m a c H}$ values are 100 and 1,000 times of the hydraulic conductivity of the infiltration layer $\left(K_{\text {inf }}[\mathrm{m} / \mathrm{s}]\right)$ and shallow horizontal hydraulic conductivity $\left(K_{\text {sat }}^{s l}[\mathrm{~m} / \mathrm{s}]\right)$, respectively. These values can be calibrated based on data. Taking both soil and macropore properties into account, the hydraulic conductivity of the subsurface is calculated as the weighted average of the macropore and the shallow soil matrix within the macropore depth (Eqn. S7 and S8).

$$
\begin{aligned}
& K_{i, V}=f_{i, \text { macH }} K_{i, \text { macV }}+\left(1-f_{i, \text { macH }}\right) K_{i, \text { satV }} \\
& K_{i, H}=f_{i, \text { macV }} K_{i, \text { macH }}+\left(1-f_{i, \text { macV }}\right) K_{i, \text { satH }}
\end{aligned}
$$

The conductivity depends on area fraction instead of volume fraction, because the hydraulic conductivity depends on how much area in the direction vertical to the flow is macropore and how much is soil or rock matrix. 


\section{S2. Monod rate law and biogeochemical redox ladder}

Under conditions where electron donors and acceptors are limited, especially anoxic conditions, the kinetics of microbe-mediated reactions can be described by the general dual Monod rate law (Monod, 1949):

$$
r=\mu_{\text {max }} B_{\text {micro }} \frac{C_{D}}{K_{m, D}+C_{D}} \frac{C_{A}}{K_{m, A}+C_{A}}
$$

Here $\mu_{\text {max }}\left[\mathrm{mol} / \mathrm{s} / \mathrm{microbe}\right.$ cell] is the rate constant, $B_{\text {micro }}$ [microbe cells $/ \mathrm{L}$ ] is the biomass concentration of microorganisms, $C_{D}$ and $C_{A}[\mathrm{~mol} / \mathrm{L}]$ are the concentrations of electron donor and acceptor, respectively. The $K_{m, D}$ and $K_{m, A}$ are the half-saturation coefficients of the electron donor and acceptors $\left[\mathrm{mol} / \mathrm{m}^{3}\right]$, respectively. When an electron donor or acceptor is not limiting, it means that $C_{D} \gg K_{m, D}$ or $C_{A} \gg K_{m, A}$, so that the term $\frac{C_{D}}{K_{m, D}+C_{D}}$ or $\frac{C_{A}}{K_{m, A}+C_{A}}$ is essentially 1 , lending to a rate that only depends on the abundance of microorganisms or one of the chemicals.

In natural subsurface where multiple electron acceptors coexist, the biogeochemical redox ladder dictates the sequence of redox reactions. That is, aerobic oxidation occurs before denitrification, which in turn occurs before iron reduction. Inhibition terms are used to account for the sequence of redox reactions as follows:

$$
r=\mu_{\text {max }} B_{\text {micro }} \frac{C_{D}}{K_{m, D}+C_{D}} \frac{C_{A}}{K_{m, A}+C_{A}} \prod \frac{K_{I, H}}{K_{I, H}+C_{H}}
$$

Here $K_{I, H}$ is the inhibition coefficient for the inhibiting chemical $H$. The inhibition term is 1 (not inhibiting) only when $C_{H} \ll K_{I, H}$. In a system where oxygen and nitrate coexist, which is common in agriculture lands, aerobic oxidation occurs first before denitrification. The denitrification rates can be represented by:

$$
r_{N O_{3}^{-}}=\mu_{\text {max }, N O_{3}^{-}} B_{\text {micro }} \frac{C_{D}}{K_{m, D}+C_{D}} \frac{C_{N O_{3}^{-}}}{K_{m, A}+C_{N O_{3}^{-}}} \frac{K_{I, O_{2}}}{K_{I, O_{2}}+C_{O_{2}}}
$$

Here $C_{D}$ is the concentration of electron donor such as organic matter or carbon ( $\mathrm{Di}$ Capua et al., 2019); $C_{\mathrm{NO}_{3}^{-}}$is the concentration of electron acceptor nitrate; $K_{I, O_{2}}$ is the inhibition coefficient of $\mathrm{O}_{2}$, or the $\mathrm{O}_{2}$ concentration at which it inhibits the reduction of nitrate. This rate law ensures that denitrification kicks in substantially only when $\mathrm{O}_{2}$ is depleted to concentration levels much lower than $K_{I, O_{2}}$ (i.e., $C_{O_{2}} \ll K_{I, O_{2}}$ ), such that the 
81 term $\frac{K_{I, O_{2}}}{K_{I, O_{2}}+C_{O_{2}}}$ approaches 1.0. If there exists an electron acceptor that is lower in the

82 redox ladder than nitrate, multiple inhibition terms are needed. For example, for iron

83 oxide, we need the following:

$84 \quad r_{\mathrm{Fe}(\mathrm{OH})_{3}}$

$85=\mu_{\max , \mathrm{Fe}(\mathrm{OH})_{3}} B_{\text {micro }} \frac{C_{D}}{K_{m, \mathrm{D}}+C_{D}} \frac{C_{\mathrm{Fe}(\mathrm{OH})_{3}}}{K_{m, \mathrm{Fe}(\mathrm{OH})_{3}}+C_{\mathrm{Fe}(\mathrm{OH})_{3}}} \frac{K_{I, \mathrm{O}_{2}}}{K_{I, \mathrm{O}_{2}}+C_{\mathrm{O}_{2}}} \frac{K_{I, \mathrm{NO}}^{-}}{K_{I, \mathrm{NO}_{3}^{-}}+C_{\mathrm{NO}_{3}^{-}}}$

86

87

88

Here $\mathrm{K}_{I, \mathrm{NO}_{3}^{-}}$is the $\mathrm{NO}_{3}{ }^{-}$concentration above which it inhibits iron reduction. The additional nitrate inhibition term means that iron reduction occurs at significant rates only when both oxygen and nitrate are low compared to their corresponding inhibition coefficients.

Note that these rate laws with dual Monod and inhibition terms can be combined with the temperature and soil moisture dependence forms discussed in the main text. Under conditions where $\mathrm{O}_{2}$ concentration is not explicitly modeled, the $\mathrm{O}_{2}$ inhibitory term (i.e., the last term in Eqn. S11) can be replaced by a function of soil moisture as follows:

$$
f\left(O_{2}\right)=\begin{aligned}
& 0\left(S_{w}<0.6\right) \\
& \left(S_{w}-0.6\right) * 2.5\left(S_{w} \geq 0.6\right)
\end{aligned}
$$

This is based on field evidence that denitrification typically occurs when soil moisture is greater than 0.6 and increases with increasing soil moisture (Brady et al., 2008). Equation 13 dictates that under dry conditions $\left(S_{w}<0.6\right)$, there is sufficient $\mathrm{O}_{2}$ that inhibits denitrification; under wet conditions $\left(S_{w} \geq 0.6\right), \mathrm{O}_{2}$ becomes limiting such that denitrification can occur. For example, the rate of denitrification can be expressed as follows:

$$
r_{N O_{3}^{-}}=\mu_{\max , N O_{3}^{-}} B_{m i c r o} \frac{C_{D}}{K_{m, D}+C_{D}} \frac{C_{N O_{3}^{-}}}{K_{m, N O_{3}^{-}}+C_{N O_{3}^{-}}} f\left(O_{2}\right) f(T) f\left(S_{w}\right)
$$

\section{S3. Model verification}

The BioRT-Flux-PIHM was verified against the benchmark CrunchTope, a widely used subsurface reactive transport model (Steefel and Lasaga, 1994;Steefel et al., 2015). Due to the limitation of CrunchTope in representing complex terrain and land-surface process, verification is performed under simplified hydrological conditions with 1-D column and constant flow rates such that it focuses on reactive transport processes such 
as advection, diffusion, dispersion, and biogeochemical reactions. Specifically, three cases of soil phosphorus, carbon, and nitrogen were verified for temporal evolution and spatial pattern of relevant solute concentrations (Figure S1 - S7). The soil phosphorus case, which involves geochemically kinetic and thermodynamic processes (i.e., apatite dissolution and phosphorous speciation), was first tested for the solution accuracy of the bulk code that was inherited from the original RT-Flux-PIHM. Soil carbon and nitrogen cases that involve microbially driven processes, such as soil carbon decomposition and mineralization, nitrification and denitrification, were further verified for the solution accuracy of the augmented BioRT module.

For the physical context, two transport scenarios were set up in the 1D column (i.e., 100 grids $\times 0.1 \mathrm{~m}$ ) with a constant flow rate of $2 \mathrm{~m} / \mathrm{d}$, i.e., advection-only case and advection + diffusion + dispersion case (Table S1).

Table S1. Flow and transport setup in the verification

\begin{tabular}{|c|c|c|c|c|c|c|}
\hline \multirow[b]{2}{*}{$\begin{array}{l}\text { \# of } \\
\text { grid }\end{array}$} & \multirow[b]{2}{*}{$\begin{array}{l}\text { Grid } \\
\text { size } \\
(\mathrm{m})\end{array}$} & \multirow[b]{2}{*}{$\begin{array}{l}\text { Flow } \\
\text { rate } \\
(\mathrm{m} / \mathrm{d})\end{array}$} & \multicolumn{2}{|c|}{ Advection-only case } & \multicolumn{2}{|c|}{ Advection + diffusion + dispersion } \\
\hline & & & $\begin{array}{l}\text { Diffusion } \\
\text { coefficient } \\
\left(\mathrm{cm}^{2} / \mathrm{s}\right)\end{array}$ & $\begin{array}{l}\text { Dispersivity } \\
\text { (m) }\end{array}$ & $\begin{array}{l}\text { Diffusion } \\
\text { coefficient } \\
\left(\mathrm{cm}^{2} / \mathrm{s}\right)\end{array}$ & $\begin{array}{l}\text { Dispersivity } \\
\text { (m) }\end{array}$ \\
\hline 100 & 0.1 & 2 & $1.0 \times 10^{-20}$ & $1.0 \times 10^{-20}$ & $1.0 \times 10^{-5}$ & 0.1 \\
\hline
\end{tabular}

\section{S3.1. Soil phosphorus processes}

Reaction network includes one kinetically controlled P-containing mineral dissolution (i.e., apatite) and three thermodynamically controlled phosphorus speciation reactions (Figure $\mathrm{S} 1$ ). The conservative tracer $\mathrm{Cl}$ is additionally included in the simulation for testing non-reactive transport processes.

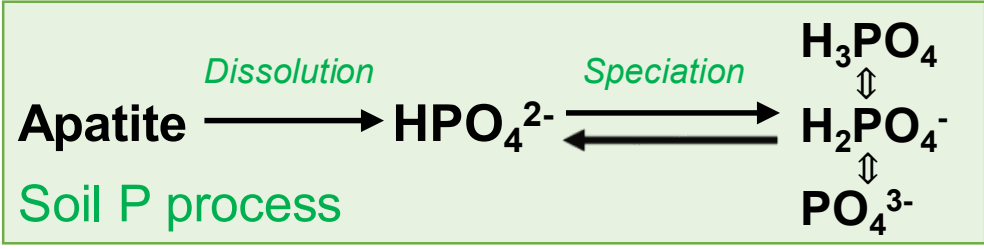

Figure S1. Soil phosphorus processes in the CrunchTope verification. 
In the advection-only case where diffusion coefficient $\left(1.0 \times 10^{-20} \mathrm{~cm}^{2} / \mathrm{s}\right)$ and dispersivity $\left(1.0 \times 10^{-20} \mathrm{~m}\right)$ are set to be negligible, we test the code's ability to capture the sharp concentration front of phosphorus species. In the other case, diffusion and dispersion processes are included with diffusion coefficient $\left(1.0 \times 10^{-5} \mathrm{~cm}^{2} / \mathrm{s}\right)$ and dispersivity $(0.1 \mathrm{~m})$ while maintaining all other flow and geochemical conditions the same as the advection-only case (Table S1). That is, in both cases, the columns are initially set up at conditions of $\mathrm{pH}=6.0, \mathrm{Cl}^{-}=1.0 \times 10^{-4}(\mathrm{~mol} / \mathrm{L}), \mathrm{HPO}_{4}{ }^{2-}=1.0 \times 10^{-7}(\mathrm{~mol} / \mathrm{L}), \mathrm{Ca}^{2+}=$ $1.0 \times 10^{-7}(\mathrm{~mol} / \mathrm{L})$, apatite $=1 \%$ (volume fraction), porosity $=0.4$. The injection condition is set up as $\mathrm{pH}=4.0, \mathrm{Cl}=1.0 \times 10^{-3}(\mathrm{~mol} / \mathrm{L}), \mathrm{HPO}_{4}{ }^{2-}=1.0 \times 10^{-5}(\mathrm{~mol} / \mathrm{L}), \mathrm{Ca}^{2+}=1.0 \times 10^{-}$ ${ }^{5}(\mathrm{~mol} / \mathrm{L})$. The phosphorous reaction network with kinetic and thermodynamic parameters are summarized in Table S2. The apatite dissolution rate is based on the Transition State Theory (TST) (Helgeson et al., 1984), as described by the following:

$$
r_{T S T}=A k\left(1-\frac{I A P}{K_{e q}}\right)
$$

Where $r_{T S T}[\mathrm{~mol} / \mathrm{s}]$ is the mineral dissolution rate, $A\left[\mathrm{~m}^{2}\right]$ is the mineral surface area, $k$ $\left[\mathrm{mol} / \mathrm{m}^{2} / \mathrm{s}\right]$ is the rate constant, IAP is the ion activity product, $K_{e q}$ is the equilibrium constant. The initial and boundary saturation index (i.e., $\log _{10}\left(I A P / K_{e q}\right)$ ) is -28.9 and 20.9 , respectively.

Table S2. Soil phosphorous reaction in the CrunchTope verification

\begin{tabular}{llll}
\hline $\begin{array}{l}\text { Phosphorous } \\
\text { reaction }\end{array}$ & Equation & $\begin{array}{l}\log _{10 \mathrm{~K}} \\
\left(\mathrm{~mol} / \mathrm{m}^{2} / \mathrm{s}\right)\end{array}$ & $\mathrm{Log}_{10} \mathrm{~K}_{\mathrm{eq}}$ \\
\hline $\begin{array}{l}\text { Apatite } \\
\text { dissolution }\end{array}$ & $\mathrm{Ca}_{5}\left(\mathrm{PO}_{4}\right)_{3}(\mathrm{OH})+4 \mathrm{H}^{+}$ & -11.0 & -3.07 \\
\hline Phosphorous & $\mathrm{H}_{3} \mathrm{PO}_{4} \rightleftharpoons \mathrm{Ca}^{2+}+3 \mathrm{HPO}_{4}^{2-}+\mathrm{H}_{2} \mathrm{O}$ & $\mathrm{H}_{2} \mathrm{PO}_{4}^{-}$ & -2.17 \\
speciation & $\mathrm{H}_{2} \mathrm{PO}_{4}^{-} \rightleftharpoons \mathrm{H}^{+}+\mathrm{HPO}_{4}^{2-}$ & -7.21 \\
& $\mathrm{HPO}_{4}^{2-} \rightleftharpoons \mathrm{H}^{+}+\mathrm{PO}_{4}^{3-}$ & -12.1 \\
\hline
\end{tabular}

Modeling results show that the code can reproduce CrunchTope results under different flow conditions (Figure S2). It captured both the sharp concentration front in the advection-only case (Figure S2a, c) and the smooth concentration front in the advection 
154 + diffusion + dispersion case (Figure S2b, d). The close match of non-reactive $\mathrm{Cl}^{-}$in the 155 temporal and spatial trend indicates a robust accuracy of transport code under varying 156 flow conditions. Result consistencies in the temporal evolution and spatial pattern of $\mathrm{H}^{+}$ 157 and total dissolved phosphorus (TP) concentration suggest a valid implementation of 158 kinetic reaction (i.e., apatite dissolution) in the reaction code.
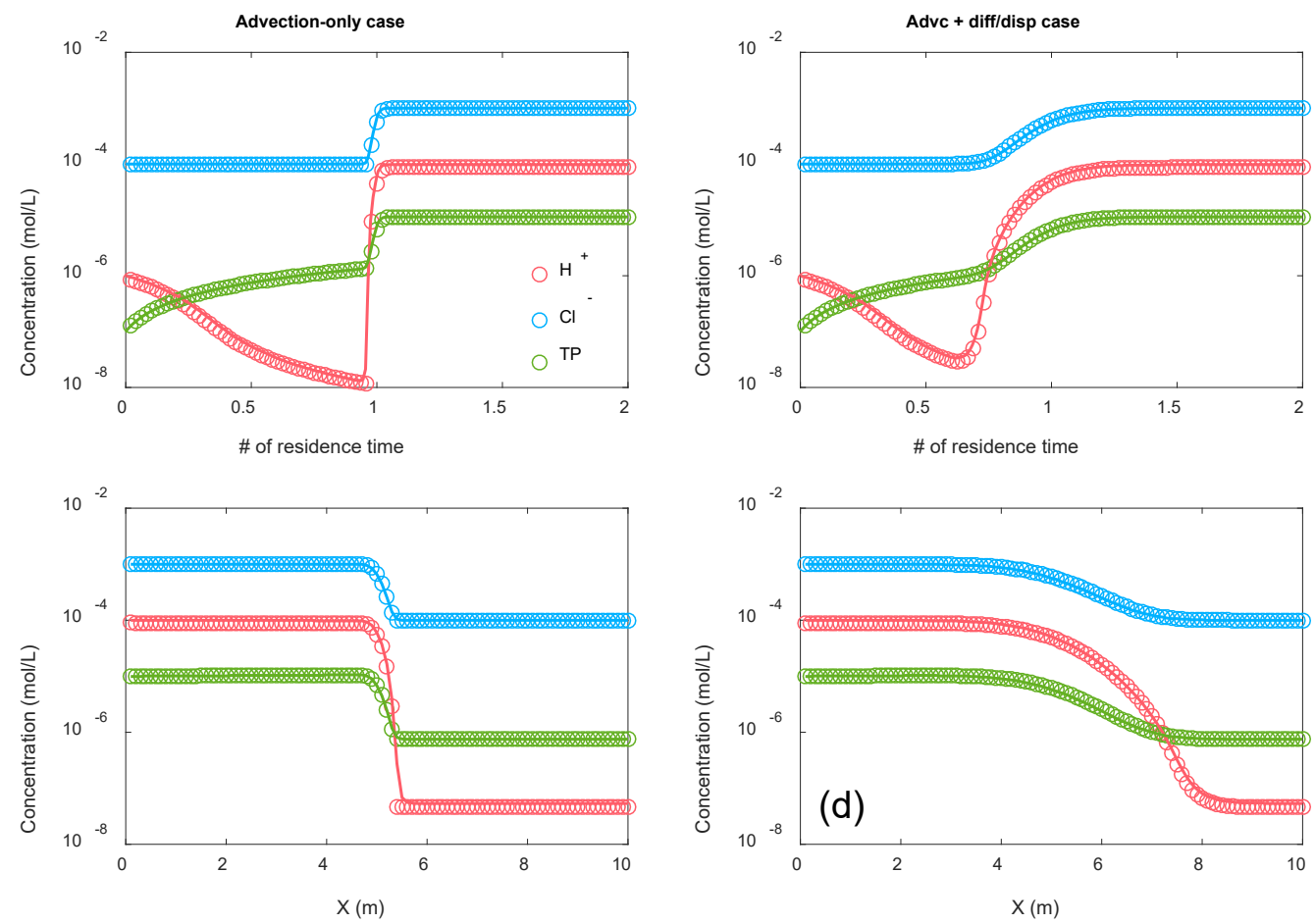

159

160

161

162

163

164

165

166

167

168 169

Figure S2. Soil phosphorus verification under advection case (left column) and advection + diffusion + dispersion case (right column). Temporal evolution of solutes at the column outlet (a, b) and spatial pattern at 0.5 residence time $(c, d)$. Circles are BioRT-Flux-PIHM results; solid lines are CrunchTope results.

Phosphate reaction was validated against CrunchTope under two transport cases (Figure S3). Phosphate speciation (i.e., fractions of $\mathrm{H}_{3} \mathrm{PO}_{4}, \mathrm{H}_{2} \mathrm{PO}_{4}^{-}, \mathrm{HPO}_{4}^{2-}, \mathrm{PO}_{4}{ }^{3-}$ to TP) is a function of solution $\mathrm{pH}$. The consistency between the model outputs suggests that the implementation of aqueous speciation code in the reaction module is robust under different $\mathrm{pH}$ conditions. 

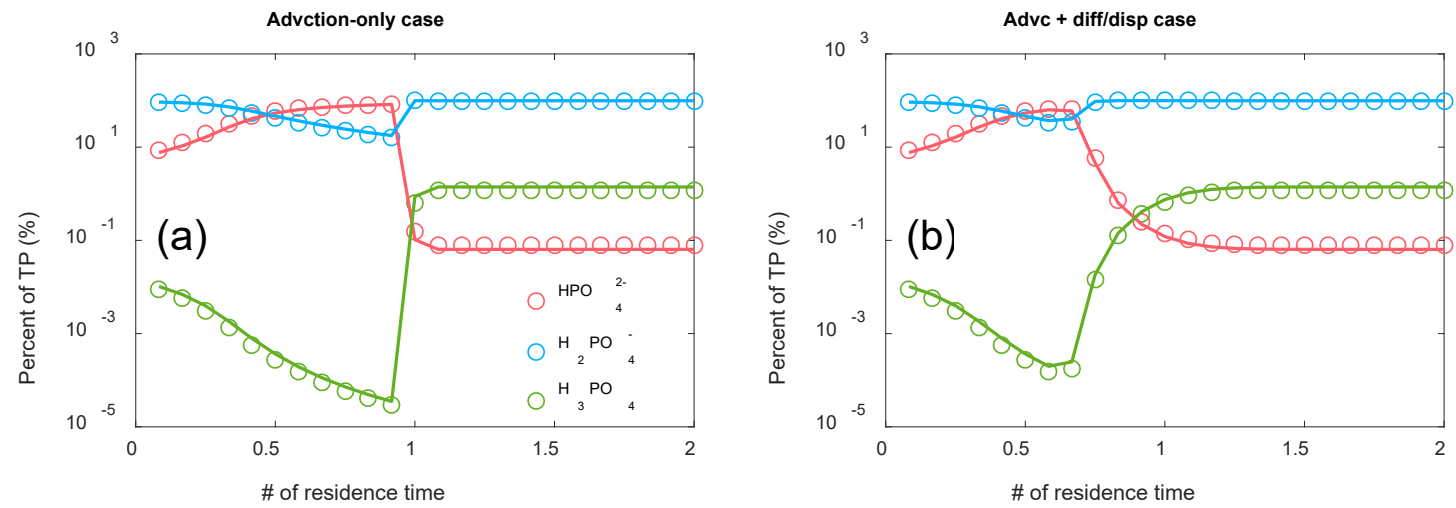

170

171

172

173

174

175

176

177

178

179

180

181

182

183

184

185

186

187

188

189

190

191

192

Figure S3. Verification of phosphate speciation calculation under advection-only case (a) and advection + diffusion + dispersion case (b). Orthophosphate (i.e., $\mathrm{PO}_{4}{ }^{3-}$ ) is not plotted due to its extreme low concentration. Circles are BioRT-Flux-PIHM results; solid lines are CrunchTope results. The close match of BioRT-Flux-PIHM and CrunchTope results indicates a robust accuracy.

\section{S3.2. Soil carbon processes}

Simulated carbon processes include soil organic carbon (SOC) decomposition and dissolved organic carbon (DOC) mineralization (Figure S4). Due to their complex chemical composition, we used the elementary form of carbohydrate $\mathrm{CH}_{2} \mathrm{O}(\mathrm{s})$ and $\mathrm{CH}_{2} \mathrm{O}(\mathrm{aq})$ to represent $\mathrm{SOC}$ and DOC, respectively. Both of these soil carbon processes are microbe-mediated reactions following the Monod rate law (Eq. 15). Soil temperature was set at $20^{\circ} \mathrm{C}$. A variety of electron acceptors (i.e., $\mathrm{O}_{2}, \mathrm{NO}_{3}{ }^{-}, \mathrm{SO}_{4}{ }^{2-}$ ) are tested to verify the code's implementation of parallel reaction pathways and biogeochemical redox ladder. Oxidation reactions occur first because soil microbes preferentially choose to reduce electron acceptors that most energy can be harvested. BioRT-Flux-PIHM is designed to model multiple microbe-mediated reactions and their interactions under dynamic redox conditions and it is critical to be able to reproduce redox ladder geochemistry (Figure S5a). The carbon case was tested under the full transport condition with advection, diffusion, and dispersion.

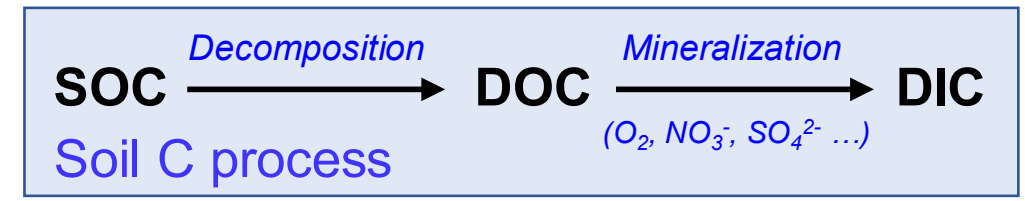

Figure S4. Soil carbon processes in the CrunchTope verification. 
194 are summarized in Table S3. For simplification, half-saturation constants $K$ of different 195 electron donors or electron acceptors were kept the same at $1.5 \times 10^{-5}(\mathrm{~mol} / \mathrm{L})$. The 196 inhibition constant of $K_{I, O_{2}(a q)}$ and $K_{I, N O_{3}^{-}}$were set at $1.5 \times 10^{-5}(\mathrm{~mol} / \mathrm{L})$ and $1.5 \times 10^{-6}$ 197 (mol/L), respectively. The chemical setup of the initial and injection conditions is listed in 198 Table S4.

199

200

Table S3. Simulated soil carbon reactions in the verification case

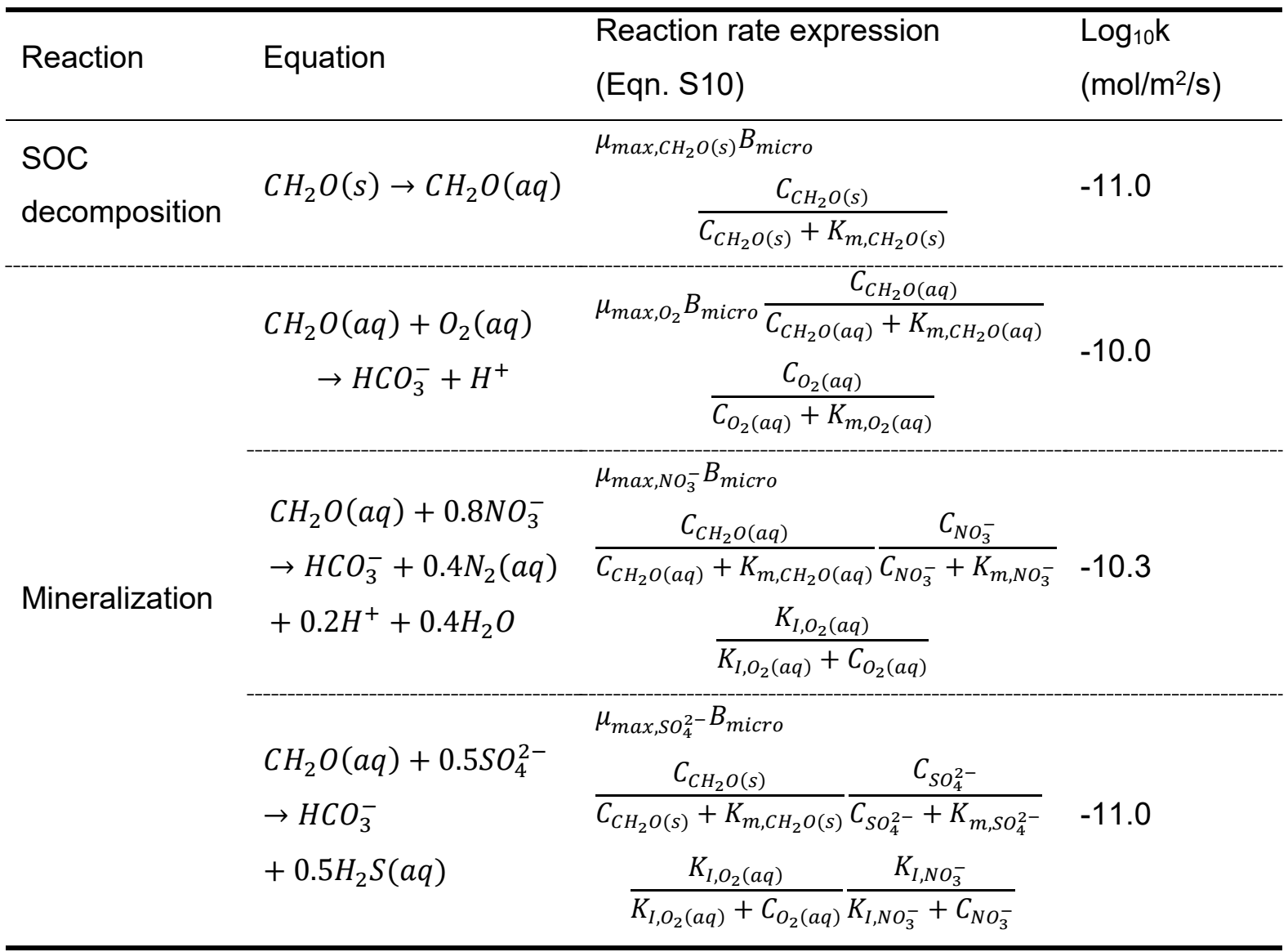

201

202 
Table S4. Initial and injection conditions in the soil carbon verification case

\begin{tabular}{lll|lll}
\hline Species & $\begin{array}{l}\text { Initial } \\
(\mathrm{mol} / \mathrm{L})\end{array}$ & $\begin{array}{l}\text { Injection } \\
(\mathrm{mol} / \mathrm{L})\end{array}$ & $\begin{array}{l}\text { Species } \\
(\text { continued })\end{array}$ & $\begin{array}{l}\text { Initial } \\
(\mathrm{mol} / \mathrm{L})\end{array}$ & $\begin{array}{l}\text { Injection } \\
(\mathrm{mol} / \mathrm{L})\end{array}$ \\
\hline $\mathrm{pH}$ & 6.0 & 4.0 & $\mathrm{SO}_{4}{ }^{--}$ & $3.0 \times 10^{-5}$ & $3.0 \times 10^{-8}$ \\
$\mathrm{CH}_{2} \mathrm{O}(\mathrm{aq})$ & $1.0 \times 10^{-8}$ & $1.0 \times 10^{-8}$ & $\mathrm{HCO}_{3}^{-}$ & $1.0 \times 10^{-8}$ & $1.0 \times 10^{-8}$ \\
$\mathrm{O}_{2}(\mathrm{aq})$ & $3.0 \times 10^{-5}$ & $3.0 \times 10^{-8}$ & $\mathrm{~N}_{2}(\mathrm{aq})$ & $1.0 \times 10^{-8}$ & $1.0 \times 10^{-8}$ \\
$\mathrm{NO}_{3}{ }^{-}$ & $3.0 \times 10^{-5}$ & $3.0 \times 10^{-8}$ & $\mathrm{H}_{2} \mathrm{~S}(\mathrm{aq})$ & $1.0 \times 10^{-8}$ & $1.0 \times 10^{-8}$ \\
\hline
\end{tabular}

Model results show that BioRT-Flux-PIHM closely matched CrunchTope results in both temporal evolution and spatial pattern of a variety of chemical species (Figure S5).

211 The concentration profile of $\mathrm{HCO}_{3}{ }^{-}$(yellow), which is the sum of three DOC mineralization 212 reactions, demonstrates that BioRT-Flux-PIHM is capable of solving parallel microbially213 mediated redox reactions. $\mathrm{O}_{2}$ (red) was consumed first and fast among all electron 214 acceptors (i.e., $\mathrm{O}_{2}, \mathrm{NO}_{3}^{-}, \mathrm{SO}_{4}{ }^{2-}$ ). $\mathrm{NO}_{3}^{-}$(green) decreased slowly at the beginning when $215 \mathrm{O}_{2}$ was still present, decreased much faster once the $\mathrm{O}_{2}$ was depleted. The same pattern 216 also applies for $\mathrm{SO}_{4}{ }^{2-}$ (blue), which decreased very slowly at the beginning when both $\mathrm{O}_{2}$ 217 and $\mathrm{NO}_{3}{ }^{-}$inhibited the $\mathrm{SO}_{4}{ }^{2-}$ reaction and decreased much faster when $\mathrm{O}_{2}$ and $\mathrm{NO}_{3}{ }^{-}$were 218 depleted. Such reaction sequence from model results reproduced redox biogeochemistry 219 ladder (inserted figure in Figure S6a). The spatial pattern of carbon solutes and other 220 electron acceptors (Figure S5b) also show consistent results with CrunchTope. In short, 221 both temporal and spatial patterns show consistent results with the benchmark 222 CrunchTope regarding soil carbon decomposition and mineralization processes, 223 suggesting the Monod rate law (e.g., substrate and inhibition terms) was correctly 224 implemented. 

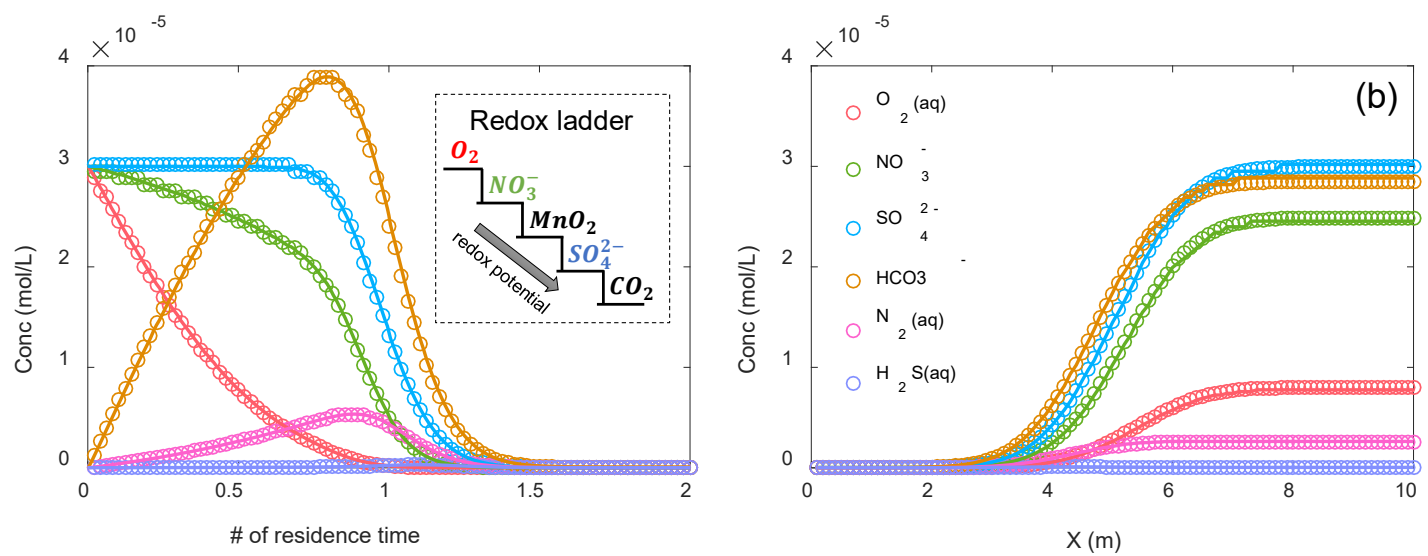

225

226

227

228

229

230

231

232

233

234

235

236

237

238

239

240

241

242

243

244

245

246

Figure S5. Model output of the time series of different electron acceptors at the column outlet (a) and spatial distribution within the column at 0.5 residence time (b). The embedded plot of the redox ladder shows biogeochemical redox ladder. Circles are BioRT-Flux-PIHM results; solid lines are CrunchTope results.

\section{S3.3. Soil nitrogen processes}

Simulated $\mathrm{N}$ processes include mineralization of dissolved organic nitrogen (DON) to ammonium $\left(\mathrm{NH}_{4}^{+}\right)$, subsequent nitrification converting $\mathrm{NH}_{4}{ }^{+}$to nitrate $\left(\mathrm{NO}_{3}{ }^{-}\right)$, and followed by denitrification reducing $\mathrm{NO}_{3}{ }^{-}$to $\mathrm{N}_{2}$ (Figure S6). Similar to soil carbon, all these sequential nitrogen transformations are microbial processes and follow the Monod rate law (Eqn. S10). Soil temperature is set at $20{ }^{\circ} \mathrm{C}$ and soil nitrogen verification was performed under the full transport condition with advection, diffusion, and dispersion.

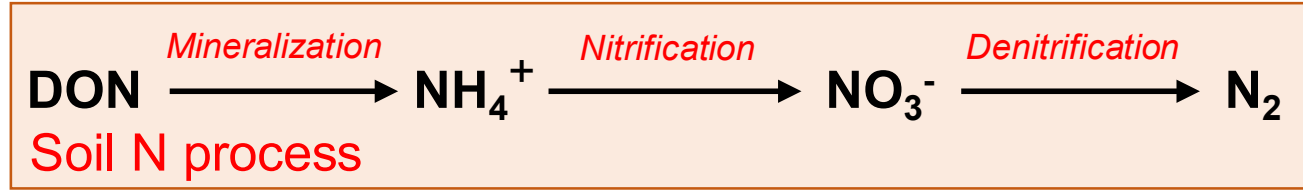

Figure S6. Soil nitrogen processes in the CrunchTope verification.

Detailed reaction network and reaction rates of soil nitrogen processes are summarized in Table S5. Half-saturation constants are as follows: $K_{m, R N H_{2}}=1.5 \times 10^{-5}$ $(\mathrm{mol} / \mathrm{L}), K_{m, O_{2}(a q)}=1.5 \times 10^{-5}(\mathrm{~mol} / \mathrm{L}), K_{m, N H_{4}^{+}}=3.0 \times 10^{-5}(\mathrm{~mol} / \mathrm{L}), K_{m, O_{2}(a q)}=4.5 \times 10^{-5}$ (mol/L). The inhibition constant $K_{I, O_{2}(a q)}$ is $3.0 \times 10^{-5}(\mathrm{~mol} / \mathrm{L})$. The chemical setup of the initial and injection condition is in Table S6. 
Table S5. Simulated soil nitrogen reactions in the verification case

\begin{tabular}{|c|c|c|c|}
\hline Reaction & Equation & $\begin{array}{l}\text { Reaction rate expression } \\
\text { (Eqn. S10) }\end{array}$ & $\begin{array}{l}\log _{10} \mathrm{k} \\
\left(\mathrm{mol} / \mathrm{m}^{2} / \mathrm{s}\right)\end{array}$ \\
\hline Mineralization & $\begin{array}{l}\mathrm{RNH}_{2}+\mathrm{O}_{2}(\mathrm{aq}) \\
+\mathrm{H}_{2} \mathrm{O} \rightarrow \mathrm{NH}_{4}^{+} \\
\quad+\mathrm{ROH}+\mathrm{OH}^{-}\end{array}$ & $\begin{array}{l}\mu_{\text {max }, R N H_{2}} B_{\text {micro }} \\
\frac{C_{R N H_{2}}}{C_{R N H_{2}}+K_{m . R N H_{2}}} \frac{C_{O_{2}(a q)}}{C_{O_{2}(a q)}+K_{m, O_{2}(a q)}}\end{array}$ & -10.0 \\
\hline Nitrification & $\begin{array}{l}\mathrm{NH}_{4}^{+}+2 \mathrm{O}_{2}(\mathrm{aq}) \rightarrow \\
\mathrm{NO}_{3}^{-}+2 \mathrm{H}^{+}+2 \mathrm{H}_{2} \mathrm{O}\end{array}$ & $\begin{array}{l}\mu_{\text {max }, N H_{4}^{+}} B_{\text {micro }} \\
\frac{C_{N H_{4}^{+}}}{C_{N H_{4}^{+}}+K_{m, N H_{4}^{+}}} \frac{C_{O_{2}(a q)}}{C_{O_{2}(a q)}+K_{m, O_{2}(a q)}}\end{array}$ & -10.0 \\
\hline Denitrification & $\begin{array}{c}\mathrm{CH}_{2} \mathrm{O}+0.8 \mathrm{NO}_{3}^{-} \rightarrow \\
\mathrm{HCO}_{3}^{-}+0.4 \mathrm{~N}_{2}(\mathrm{aq}) \\
+0.2 \mathrm{H}^{+}+0.4 \mathrm{H}_{2} \mathrm{O}\end{array}$ & $\begin{array}{c}\frac{C_{\mathrm{CH}_{2} \mathrm{O}}}{\mathrm{C}_{\mathrm{CH}_{2} \mathrm{O}}+K_{m, \mathrm{CH}_{2} \mathrm{O}} \mathrm{B}_{\text {micro }}} \frac{C_{\mathrm{NO}_{3}^{-}}}{C_{\mathrm{NO}_{3}^{-}}+K_{m, \mathrm{NO}_{3}^{-}}} \\
\frac{K_{I, \mathrm{O}_{2}(a q)}}{K_{I, \mathrm{O}_{2}(a q)}+C_{\mathrm{O}_{2}(a q)}}\end{array}$ & -11.0 \\
\hline
\end{tabular}

248

250

251

252

253

254

255

256

257

258

259

260

261

Table S6. Initial and injection conditions in the soil nitrogen verification case

\begin{tabular}{lll|lll}
\hline Species & $\begin{array}{l}\text { Initial } \\
(\mathrm{mol} / \mathrm{L})\end{array}$ & $\begin{array}{l}\text { Injection } \\
(\mathrm{mol} / \mathrm{L})\end{array}$ & $\begin{array}{l}\text { Species } \\
(\text { continued })\end{array}$ & $\begin{array}{l}\text { Initial } \\
(\mathrm{mol} / \mathrm{L})\end{array}$ & $\begin{array}{l}\text { Injection } \\
(\mathrm{mol} / \mathrm{L})\end{array}$ \\
\hline $\mathrm{pH}$ & 6.0 & 4.0 & $\mathrm{NO}_{3}^{-}$ & $3.0 \times 10^{-5}$ & $3.0 \times 10^{-8}$ \\
$\mathrm{O}_{2}(\mathrm{aq})$ & $3.0 \times 10^{-5}$ & $3.0 \times 10^{-8}$ & $\mathrm{HCO}_{3}^{-}$ & $1.0 \times 10^{-5}$ & $1.0 \times 10^{-5}$ \\
$\mathrm{NH}_{4}{ }^{+}$ & $1.0 \times 10^{-8}$ & $1.0 \times 10^{-8}$ & $\mathrm{~N}_{2}(\mathrm{aq})$ & $1.0 \times 10^{-8}$ & $1.0 \times 10^{-8}$ \\
\hline
\end{tabular}

Model results show that BioRT closely matched CrunchTope results and reproduced temporal evolution and spatial pattern of a variety of nitrogen species (Figure S7). Products of $\mathrm{NH}_{4}{ }^{+}, \mathrm{NO}_{3}{ }^{-}$, and $\mathrm{N}_{2}(\mathrm{aq})$, which mainly originates from soil organic nitrogen in a forest (no fertilizer), are sensitive to redox conditions as nitrification is an aerobic process whereas denitrification occurs largely under anoxic conditions. The $\mathrm{O}_{2}$ (aq) (red) was consumed (decreasing) by the mineralization for production of $\mathrm{NH}_{4}{ }^{+}$ (green) and by the nitrification for production of $\mathrm{NO}_{3}{ }^{-}$(blue). The $\mathrm{O}_{2}(\mathrm{aq})$ depletion led to the decrease in the production of $\mathrm{NH}_{4}{ }^{+}$and $\mathrm{NO}_{3}^{-}$; but increased the generation of $\mathrm{N}_{2}(\mathrm{aq})$ (purple) via denitrification. The spatial patterns of nitrogen species (Figure S7b) also show the same results as the CrunchTope. The nitrogen case demonstrates the code capability to model sequential microbial processes under dynamic redox conditions. 

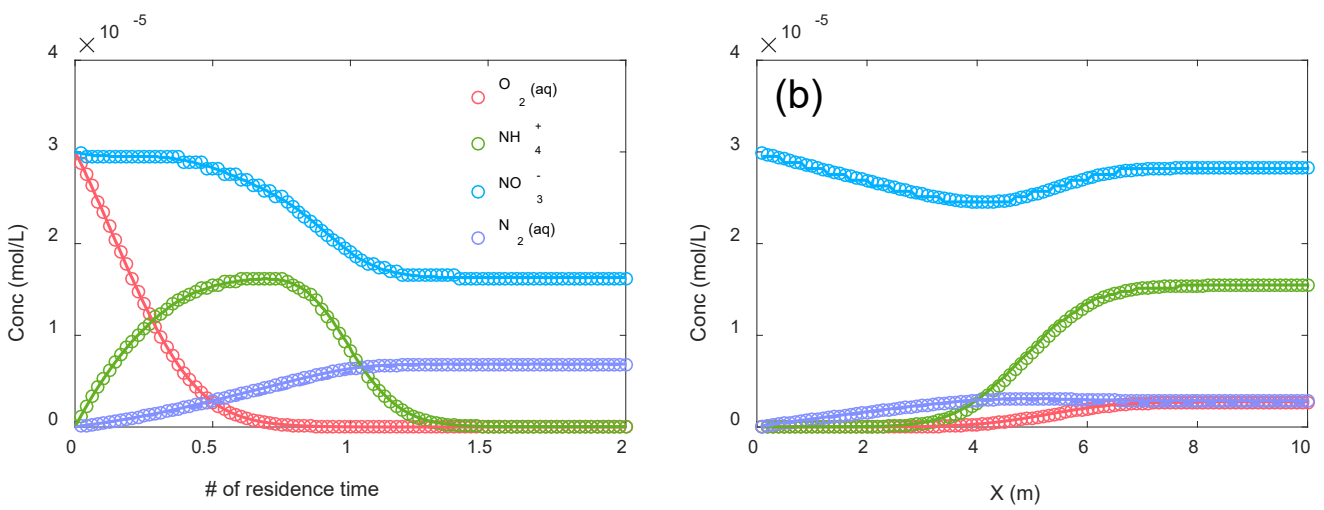

263 Figure S7. Model output of temporal evolution of $\mathrm{N}$ species at the column outlet (a) and spatial

264 distribution within the column at 0.5 residence time (b). Circles are BioRT-Flux-PIHM results and 265 solid lines are CrunchTope results.

\section{S3.4. Validation performance summary}

Model validation performance for above-mentioned cases using percent bias (PBIAS) and Nash Sutcliffe efficiency (NSE) is summarized in Table S7. The optimal

270 value of PBIAS is 0 , with low-magnitude values indicating accurate model simulation 271 (Moriasi et al., 2007). Positive values indicate model underestimation bias, and negative 272 values indicate model overestimation bias. NSE ranges between $-\infty$ and 1 , with NSE = 2731 being the perfect fit (Moriasi et al., 2007).

Table S7. Model validation performance

\begin{tabular}{lll|ll}
\hline Process & Transport & Species & PBIAS (\%) & NSE \\
\hline Phosphorus & Advection-only & $\mathrm{H}^{+}$ & 3.1 & 0.96 \\
(Fig S2, S3) & & $\mathrm{Cl}^{-}$ & 1.0 & 0.99 \\
& & $\mathrm{TP}$ & 1.0 & 0.99 \\
& & $\mathrm{HPO}_{4}{ }^{2-}$ & -2.3 & 0.99 \\
& & $\mathrm{H}_{2} \mathrm{PO}_{4}{ }^{-}$ & 1.7 & 0.99 \\
& & $\mathrm{H}_{3} \mathrm{PO}_{4}$ & 4.6 & 0.95 \\
\cline { 2 - 5 } & Advection + & $\mathrm{H}^{+}$ & 2.7 & 0.97 \\
& diffusion + & $\mathrm{Cl}^{-}$ & -0.27 & 1.0 \\
& dispersion & $\mathrm{TP}^{-}$ & -0.20 & 1.0 \\
& & $\mathrm{HPO}_{4}{ }^{2-}$ & -3.2 & 0.98 \\
& & & &
\end{tabular}




\begin{tabular}{lll|ll}
\hline & & $\mathrm{H}_{2} \mathrm{PO}_{4}{ }^{-}$ & 1.4 & 0.99 \\
& & $\mathrm{H}_{3} \mathrm{PO}_{4}$ & 4.5 & 0.96 \\
\hline Carbon & Advection + & $\mathrm{O}_{2}(\mathrm{aq})$ & 2.2 & 0.98 \\
(Fig S5) & diffusion + & $\mathrm{NO}^{-}$ & -1.4 & 0.99 \\
& dispersion & $\mathrm{SO}_{4}{ }^{-{ }^{-}}$ & -0.2 & 0.99 \\
& & $\mathrm{HCO}_{3}{ }^{-}$ & 1.1 & 0.99 \\
& & $\mathrm{~N}_{2}(\mathrm{aq})$ & 2.0 & 0.98 \\
& & $\mathrm{H}_{2} \mathrm{~S}(\mathrm{aq})$ & 2.5 & 0.98 \\
\hline Nitrogen & Advection + & $\mathrm{O}_{2}(\mathrm{aq})$ & 2.2 & 0.99 \\
(Fig S7) & diffusion + & $\mathrm{NH}_{4}{ }^{+}$ & 1.5 & 1.0 \\
& dispersion & $\mathrm{NO}_{3}{ }^{-}$ & -1.3 & 0.98 \\
& & $\mathrm{~N}_{2}(\mathrm{aq})$ & 1.8 & 0.99 \\
\hline
\end{tabular}

276

277 


\section{Reference}

279 Brady, N. C., Weil, R. R., and Weil, R. R.: The nature and properties of soils, Prentice Hall Upper Saddle 280 River, NJ, 2008.

281 Di Capua, F., Pirozzi, F., Lens, P. N. L., and Esposito, G.: Electron donors for autotrophic denitrification, 282 Chemical Engineering Journal, 362, 922-937, https://doi.org/10.1016/j.cej.2019.01.069, 2019.

283 Helgeson, H. C., Murphy, W. M., and Aagaard, P.: Thermodynamic and kinetic constraints on reaction rates 284 among minerals and aqueous solutions. II. Rate constants, effective surface area, and the hydrolysis of 285 feldspar, Geochimica et Cosmochimica Acta, 48, 2405-2432, 1984.

286 Monod, J.: The growth of bacterial cultures, Annual review of microbiology, 3, 371-394, 1949.

287 Moriasi, D. N., Arnold, J. G., Van Liew, M. W., Bingner, R. L., Harmel, R. D., and Veith, T. L.: Model evaluation 288 guidelines for systematic quantification of accuracy in watershed simulations, T Asabe, 50, 885-900, 2007. 289 Shi, Y., Davis, K. J., Duffy, C. J., and Yu, X.: Development of a coupled land surface hydrologic model and 290 evaluation at a critical zone observatory, Journal of Hydrometeorology, 14, 1401-1420, 2013.

291 Steefel, C., Appelo, C., Arora, B., Jacques, D., Kalbacher, T., Kolditz, O., Lagneau, V., Lichtner, P., Mayer, K. 292 U., and Meeussen, J.: Reactive transport codes for subsurface environmental simulation, Computational 293 Geosciences, 19, 445-478, 2015.

294 Steefel, C. I., and Lasaga, A. C.: A coupled model for transport of multiple chemical species and kinetic 295 precipitation/dissolution reactions with application to reactive flow in single phase hydrothermal systems, 296 American Journal of science, 294, 529-592, 1994. 